Arch. Dis. Childh., 1968, 43, 415.

\title{
Severe Bronchopneumonia in the Young Child
}

\author{
R. S. JONES, J. B. OWEN-THOMAS, and M. J. BOUTON \\ From Alder Hey Children's Hospital, Liverpool; and University of Oxford, \\ Nuffield Institute for Medical Research
}

The majority of infants who develop infections of the lower respiratory tract respond satisfactorily to standard methods of treatment, with antibiotics, oxygen, humidity, and, when necessary, tube feeding (Simpson and Flenley, 1967; Disney et al., 1960; Heycock and Noble, 1962). A proportion, in our experience approximately $12 \%$, fails to respond, and it is with this group that this paper is concerned. This figure is appreciably higher than the $1-4 \cdot 6 \%$ reported by these authors and by Morrison (1955) and High (1957), since we are considering only those with $x$-ray opacity in the lung fields at some time during the illness. We agree with Disney et al. (1960) and Heycock and Noble (1962) that it is not possible to separate off bronchiolitis from bronchopneumonia. Deterioration in the former is nearly always followed by the appearance of opacities in the lung fields before or after starting assisted ventilation.

\section{Material and Methods} I).

The 70 patients were divided into three groups (Table

Group 1: Pneumonia presenting with severe circulatory failure. Attention has already been drawn to this condition (Jones, 1966), but it has not been described fully. It occurs after the first week of life and must therefore be distinguished from neonatal pneumonia, which is commonly attributed to events immediately concerned with birth (Bernstein and Wang, 1961).

Group 2: Pneumonia (other than staphylococcal) presenting with respiratory symptoms: these make up the majority of the cases.

Group 3: Staphylococcal pneumonia. This has long been recognized as a serious form of pneumonia (Hendren and Haggerty, 1958; Koch, Carson, and Donnell, 1959; Pryles, 1958). Groff, Randolph, and Blades (1966) stressed the necessity for early, energetic treatment. Once a bron hopulmonary fistula has formed, assisted ventilation becomes technically extremely difficult (Fisk, 1966).

One-third of the cases were admitted directly to the Intensive Care Unit. The remainder were transferred from other wards in the hospital because deterioration

Received February 19, 1968. had occurred. In all, the severity of the pneumonia was such that a fatal termination might have been anticipated.

\section{Results}

Pneumonia presenting with circulatory failure. The striking features of this group were the short history, often without respiratory symptoms, and the early occurrence of circulatory failure leading to a state of collapse even before respiratory signs appeared to draw attention to the lungs as the primary site of disease. It differed strikingly from the more usual form of bronchopneumonia where respiratory symptoms are prominent from the outset and where, if the disease progresses, respiratory failure and finally circulatory failure appear in that order, a sequence that usually takes several days. On the other hand, in the group about to be described, circulatory failure preceded respiratory failure and led rapidly to death.

In the group of 12 patients, the ages were from 7 days to 6 months; in the majority the illness occurred within the first month of life, emphasizing that it is a disease of early infancy. Pallor, mottled cyanosis, refusal of feeds, a general lack of response to stimuli and lack of interest in surroundings, together with stupor or light coma were common early symptoms. An upper respiratory tract infection was often suspected by the general practitioner, but the obvious severity of the illness was out of keeping with this diagnosis.

An important early finding which was often

TABLE I

Bronchopneumonia in 70 Patients

\begin{tabular}{l|c|c|c}
\hline \multicolumn{1}{c|}{ Groups } & $\begin{array}{c}\text { No. of } \\
\text { Cases }\end{array}$ & $\begin{array}{r}\text { No. of } \\
\text { Deaths }\end{array}$ & Age Range \\
\hline 1. Circulatory failure & 12 & 9 & 7 dy. -6 mth. \\
2. Respiratory failure & 45 & 19 & 10 dy. $-10 \mathrm{mth}$. \\
3. Staphylococcal & 13 & 8 & 14 dy. $-10 \mathrm{mth}$. \\
\hline
\end{tabular}


overlooked was oliguria or anuria due to renal failure, secondary to severe circulatory failure. The pulse was small in volume and rapid. The cardiac impulse was feeble. There was slight hyperpnoea, or irregular respiration with brief periods of apnoea. These are important signs of respiratory failure due to central depression, and may herald a complete circulatory arrest. A few fine râles were sometimes audible over the lung fields, and the chest $x$-ray was usually normal at the time of presentation. The $\mathrm{PCO}_{2}$ (capillary blood) was normal or low, but if circulatory failure had led to central depression of respiration, it was high. A marked base deficit was always present due to poor tissue oxygenation consequent upon a low cardiac output.

Despite a short history of 24-48 hours, blood urea at the time of admission was remarkably high (Table II). The serum sodium and potassium also tended to be high, and the chloride normal or high. The white cell count was normal or raised, and the differential count usually normal.

All but one of these patients were ventilated with intermittent positive pressure ventilation (IPPV) using a nasal endotracheal tube. In the patient not ventilated (Case 1, Table II), ventilation seemed adequate and the $\mathrm{PCO}_{2}$ was $26 \mathrm{~mm}$. Hg. Peritoneal dialysis was performed on account of anuria and a rising blood urea (256 mg./100 ml.). Death occurred quite suddenly 2 hours later during the dialysis. In retrospect, when peritoneal dialysis is required in this group, ventilation should probably always be begun first, because respiratory failure may occur very quickly and dialysis itself embarrasses ventilation. The effect of the dialysing volume on intraperitoneal pressure was measured in one patient. The initial pressure was $11 \mathrm{~cm}$. saline above the mid axillary line, and the final pressure after the introduction of $4 \mathrm{ml} . / \mathrm{kg}$. of fluid into the peritoneal cavity was $35 \mathrm{~cm}$. Case 6 was ventilated for 5 days and was also dialysed. $\mathrm{He}$ made a complete recovery, and subsequent investigation of the renal tract revealed no underlying abnormality. Case 7 required ventilation for only a few hours and was not dialysed; he subsequently made a complete recovery. Case 9 required ventilation for 5 days and recovered; he was not dialysed but his blood urea did not return to normal until the sixth day. There was a persistent tendency to oedema despite restriction of fluids, and there was a persistent base deficit of 6-7 mEq/l. during the first 8 days. Serum potassium was raised at first but later became subnormal.

In all 3 survivors, râles appeared in the chest at some stage during ventilation, and at this time opacities were visible on $x$-ray examination. These were never dense or persistent, and resolved within a week.

In the remaining patients death occurred within 48 hours in all instances and in some within a few hours of admission. This was always due to circulatory failure which failed to respond to treatment. In half of these, râles became audible over the lung fields, and opacities became visible on $x$-ray. Respiratory insufficiency due to consolidation was not the cause of death, however. Gross respiratory failure with high $\mathrm{PCO}_{2}$ levels and severe hypoxia appeared always to be secondary to a low cardiac output and central depression of respiration.

The criteria for ventilation in this group were,

TABIE

Pneumonia wîนh

\begin{tabular}{|c|c|c|c|c|c|c|c|}
\hline Patient No. & Age (wk.) & $\begin{array}{c}X \text {-ray } \\
\text { On Admission }\end{array}$ & $\underset{(\mathrm{mEq} / \mathrm{l} .)}{\mathrm{Na}}$ & $\underset{(\mathrm{mEq} / \mathrm{l} .)}{\mathbf{K}}$ & $\underset{(\mathrm{mEq} / \mathrm{l} .)}{\mathrm{Cl}}$ & $\begin{array}{c}\text { Urea } \\
\text { (mg./100 ml.) }\end{array}$ & $p \mathrm{H}$ \\
\hline $\begin{array}{r}1 \\
2 \\
3 \\
4 \\
5 \\
6 \\
7 \\
8 \\
9 \\
10 \\
11 \\
12 \\
\end{array}$ & $\begin{array}{r}2 \\
3 \\
24 \\
3 \\
1 \\
16 \\
1 \\
12 \\
2 \\
1 \\
1 \\
1\end{array}$ & $\begin{array}{c}\text { Normal } \\
\text { \#’' } \\
\text { Opacity } \\
\text { Normal } \\
\text { Opacity } \\
\text { \#, } \\
\text { Normal } \\
\text { Opacity } \\
\text { Normal } \\
\text { " }\end{array}$ & $\begin{array}{l}152 \\
141 \\
125 \\
150 \\
140 \\
146 \\
137 \\
137 \\
136 \\
142 \\
153 \\
153\end{array}$ & $\begin{array}{l}7 \cdot 5 \\
6 \cdot 9 \\
7 \cdot 2 \\
7 \cdot 6 \\
6 \cdot 3 \\
5 \cdot 2 \\
4 \cdot 3 \\
5 \cdot 6 \\
7 \cdot 0 \\
6 \cdot 4 \\
7 \cdot 8 \\
4 \cdot 5\end{array}$ & $\begin{array}{r}127 \\
89 \\
102 \\
136 \\
122 \\
120 \\
116 \\
111 \\
120 \\
115 \\
130 \\
122\end{array}$ & $\begin{array}{l}256 \\
154 \\
200 \\
348 \\
244 \\
260 \\
144 \\
114 \\
304 \\
190 \\
228 \\
240\end{array}$ & $\begin{array}{l}6.9 \\
6.98 \\
7.21 \\
7.51 \\
7.5 \\
6 \cdot 82 \\
7.01 \\
6.95 \\
6.99 \\
6.99 \\
7.15 \\
7 \cdot 11\end{array}$ \\
\hline Mean & & & 143 & $6 \cdot 3$ & 118 & 223 & 7.05 \\
\hline
\end{tabular}


therefore, (1) respiratory failure secondary to circulatory failure, i.e. ventilation required as part of the treatment of a state of 'collapse'; (2) respiratory failure due to progression of disease in the lung; and (3) failure before dialysis for renal failure.

Pneumonia presenting with respiratory symptoms, with or without respiratory failure. In the majority of infants with bronchopneumonia, the illness begins with respiratory symptoms and may progress to respiratory failure. Circulatory failure, when it occurs, is a late event. There were 45 in this group (Table III). 12 required endotracheal intubation in order to remove secretions and only 2 of these died. 30 had to be ventilated and 17 of these died. However, of the 17 who died, 2 had associated congenital heart disease which was severe, 3 had tracheo-oesophageal fistulas, and 4 had cerebral lesions which probably played a part in the deaths. Thus, in approximately half of those who died following ventilation, there was an important associated lesion. Only 3 of the 45 admitted in this group recovered without intubation or ventilation.

Of the 12 patients treated with endotracheal intubation and not ventilated, 4 had congenital heart disease and 1 of these died. The other death was in an infant with severe retrognathia.

In all 45 patients the disease had progressed before admission to the Unit to the point of respiratory failure. They had become cyanosed when breathing 30-40\% oxygen, and the $\mathrm{PCO}_{2}$ exceeded $50 \mathrm{~mm}$. $\mathrm{Hg}$. In 3 there was no circulatory failure, and they recovered without the necessity for additional treatment. In the remainder the blood pressure was low or unrecordable and
TABLE III

Cases Requiring Ventilation or Naso-tracheal Intubation

\begin{tabular}{l|c|c|c|c}
\hline \multicolumn{1}{c|}{ Group } & No. & Ventilated & $\begin{array}{c}\text { Nasal } \\
\text { Tube }\end{array}$ & $\begin{array}{c}\text { Not } \\
\text { Venti- } \\
\text { lated or } \\
\text { Intu- } \\
\text { bated }\end{array}$ \\
\hline $\begin{array}{ll}\text { 1. Circulatory failure } \\
\text { 2. Respiratory failure }\end{array}$ & $\begin{array}{r}12(9)^{\star} \\
45(19)^{\star}\end{array}$ & $\begin{array}{c}11(8)^{\star} \\
30(17)^{\star}\end{array}$ & $\begin{array}{c}12(1)^{\star} \\
8\end{array}$ & 0 \\
3. Staphylococcal .. & $13(7)^{\star}$ & $8(7)^{\star}$ & 0 & 5 \\
\hline Total .. & $70(35)^{\star}$ & $49(32)^{\star}$ & $13(3)^{\star}$ & 8 \\
\hline Mortality (\%) & 50 & 65 & 23 & 0 \\
\hline
\end{tabular}

$\star$ Deaths.

respiratory effort was reduced, irregular, or absent. Immediate resuscitative measures were required. These rapidly restored the pulse and blood pressure, and subsequent treatment was with nasal intubation alone (12 patients) or with ventilation.

The primary reason for cardio-respiratory failure at this point appeared to be obstruction to the airway by viscid mucoid material. Treatment was continued with intubation alone if, after resuscitation, the degree of respiratory effort was slight, there was no cyanosis in $30 \%$ oxygen, and the $\mathrm{PCO}_{2}$ was less than $70 \mathrm{~mm}$. $\mathrm{Hg}$. If these criteria were not met the patients were ventilated.

During ventilation it was usual for the râles and the areas of opacity on $x$-ray to extend during the first 24-48 hours. At this time the $\mathrm{PcO}_{2}$ was frequently in the range $70-90 \mathrm{~mm}$. $\mathrm{Hg}$. In those who recovered, by the fourth to fifth day of ventilation the râles diminished, the $\mathrm{PCO}_{2}$ fell to normal, and the infant's mucous membranes remained pink

II

Circulatory Failure

\begin{tabular}{|c|c|c|c|c|c|c|c|}
\hline $\begin{array}{c}\mathrm{PCO}_{2} \\
(\mathrm{~mm} . / \mathbf{H g})\end{array}$ & $\begin{array}{c}\text { St. Bicarb } \\
(\mathrm{mEq} / \mathrm{l} .)\end{array}$ & $\mathrm{Hb}(\%)$ & WBC/cu.mm. & Dialysis & $\begin{array}{l}\text { Ventilated } \\
\text { (time in } \\
\text { hours) }\end{array}$ & D.ath & Pathology * \\
\hline $\begin{array}{r}26 \\
34 \\
45 \\
28 \\
24 \\
110 \\
20 \\
80 \\
47 \\
35 \\
22 \\
36\end{array}$ & $\begin{array}{r}12 \cdot 5 \\
8 \cdot 6 \\
16 \cdot 5 \\
9 \cdot 5 \\
8 \cdot 5 \\
7 \cdot 0 \\
8 \cdot 0 \\
7 \cdot 0 \\
10 \cdot 0 \\
7 \cdot 5 \\
10 \cdot 5 \\
13\end{array}$ & $\begin{array}{r}120 \\
103 \\
107 \\
100 \\
112 \\
90 \\
95 \\
-110 \\
96 \\
113 \\
120\end{array}$ & $\begin{array}{r}38,000 \\
7,000 \\
18,000 \\
10,000 \\
30,000 \\
9,000 \\
15,000 \\
- \\
19,000 \\
12,000 \\
7,000 \\
19,000\end{array}$ & $\begin{array}{l}+ \\
+\end{array}$ & $\begin{array}{r}- \\
3 \\
102 \\
30 \\
28 \\
88 \\
30 \\
6 \\
9 \\
6 \\
4\end{array}$ & $\begin{array}{l}+ \\
+ \\
+ \\
+ \\
+\end{array}$ & $\begin{array}{l}\mathrm{Pn} \\
\mathrm{Br} \\
\mathrm{Br} \\
\mathrm{H} \\
\mathrm{Br} \\
- \\
- \\
\mathrm{Br} \\
- \\
\mathrm{H} \\
\mathrm{H} \\
\mathrm{Br}\end{array}$ \\
\hline 57 & $9 \cdot 9$ & & & & & & \\
\hline
\end{tabular}


when ventilated on air. In addition, the extent of the opacity on $x$-ray had also started to diminish.

Death in this group was due to failure of the disease to resolve during the period of ventilation. Râles became coarse, widespread, and bilateral, but tubular breathing was uncommon. Pleural complications and spread of infection elsewhere did not occur. The $\mathrm{PCO}_{2}$ remained high, 80-100 $\mathrm{mm} . \mathrm{Hg}$, and the patient was frequently cyanosed when ventilated with over- $50 \%$ oxygen. The opacities on the chest $x$-ray extended and became bilateral. The material aspirated from the endotracheal tube was mucoid or slightly purulent, but not frankly purulent. A variety of organisms was isolated: Haemophilus influenzae, Streptococcus viridans, klebsiellae, Esch. coli, B. proteus, and Ps. pyocyanea. The flora tended to vary in a given subject and no consistent organism was isolated. The antibiotic treatment used was prescribed in the light of the bacteriological results after initial intramuscular penicillin and streptomycin.

The lungs became progressively stiffer, and higher inspiratory pressures were required to ventilate them. Progressive respiratory failure ultimately led to final cardiac arrest. Congestive cardiac failure was not observed. Slight enlargement of the liver was sometimes seen, but this was attributed to the downward displacement of the diaphragm as a consequence of positive pressure ventilation. Renal and cerebral complications were not seen unless an episode of severe circulatory failure had occurred. Hypoxic brain injury occurred in one instance.

Staphylococcal pneumonia. Thirteen infants were admitted between the ages of 2 weeks and 10 months. Admission was precipitated in each patient by an episode of severe respiratory failure frequently accompanied by circulatory failure, which would have proved fatal without resuscitative measures. In all but one patient this was due to the formation of a pneumothorax or pyopneumothorax. The one exception was an infant of 14 weeks, in whom an abscess ruptured into the airway so that respiratory failure was due to obstruction to the air passages with pus. An endotracheal tube was passed and the airway was aspirated. He had to be ventilated for 72 hours, and recovered.

There were 5 other survivors. In 1 , an empyema had to be aspirated; in addition, a subphrenic abscess formed but absorbed without active measures and he made a full recovery. The remaining 4 developed tension pneumothoraces; these were controlled by an intrapleural drain and underwater seal. They did not require assisted ventilation; the bronchopleural fistula sealed off and they made a complete recovery.

Seven died, and in each instance the sequence of events was almost identical: an empyema or pyopneumothorax formed and had to be drained; this temporarily relieved respiratory failure but it recurred and positive pressure ventilation had to be used. This controlled the situation for a time, but ultimately it got out of control due to the volume of inspired gas which passed directly through the fistula without ventilating the lung.

\section{Findings at Necropsy}

The pulmonary lesions found at necropsy could be divided into 3 main types.

Type 1. A fibrinous and purulent exudate filled the airspaces-both bronchiolar lumina and alveolar spaces, i.e. classical purulent bronchopneumonia. This was found in 5 of the 9 who died in the group presenting with circulatory failure, and in 13 of the 19 who died in the group presenting with respiratory failure.

In 3 of those in the first group and in 4 in the second group, an additional lesion was found which merits description. The muco-fibrinous exudate in the air spaces was more eosinophilic and opaque, and was plastered against and adherent to the walls of the atrial chambers in the manner of a 'hyaline membrane'. At the same time the complement of polymorphs in the exudate was less, so that the net result was indeed a great similarity in appearance to that seen in primary hyaline membrane disease of the newborn. The stage of the disease at which this membrane was seen varied, and it seems unlikely that it occurs during the natural course of the disease.

The duration of ventilation in the group of 12 with circulatory failure and showing this hyaline change was quite short, 30,9 , and 6 hours. Amongst the 45 cases of Group 2 this hyaline change was only seen after prolonged ventilation of $11,13,14$, and 13 days. The mean duration of ventilation of the 30 cases that were ventilated in the latter group was 8 days (range 6 hours to 25 days), so that some who did not show the changes had been ventilated for longer periods. Despite the lack of correlation with duration of ventilation, it may well be therapeutically induced. Once formed it appears incapable of resolution. In one case this appearance was accompanied by all the features of an organizing pneumonia; it is tempting to assume that the development of the membrane favours non-resolution of the pneumonia, and that the membrane itself can only heal by fibrosis. 
Type 2. The pathological features found were confined to the alveolar septa. There was no exudation in the alveolar spaces, but there was hyperaemia of the alveolar capillaries, thickening of alveolar septa, and infiltration by macrophages, histiocytes, and a few polymorphs, which sometimes spilled over into the alveolar spaces. There was no evidence of any lesion of the bronchiolar walls and therefore the term acute pneumonitis is preferred. The aetiology of the condition is not clear. There is a close resemblance to the changes found in 'cot deaths'. In view of the recent suggestion (Parish, Barrett, and Coombs, 1960a; Parish et al., 1960b) that an allergic anaphylactic reaction to milk proteins plays an important part, we have examined these and cases of cot deaths using frozen sections and fluorescent techniques. A globulincontaining exudate can very often be shown in the alveolar spaces by use of anti-human globulin conjugated with fluorescein, but we have been unable to show that this globulin is an immune globulin directed against milk proteins. Furthermore, an anti-serum prepared in a rabbit against milk proteins failed to give positive fluorescence when the lungs were treated with it and then challenged with an anti-rabbit globulin conjugated with fluorescein. As this procedure has given positive results in cases dying after aspiration of stomach contents, we deduce that there were no free milk proteins in the lungs of our cases.

There was no positive correlation between the type of pulmonary changes and the severity of circulatory failure, but in $\mathbf{2}$ of the cases presenting with this feature the kidney had suffered severe damage. The tubules of the medulla and of the juxtamedullary cortex were filled with brownish casts, and their epithelia showed all stages of necrosis including complete disintegration of the basement membrane. Damage to the cortex and proximal tubules was less evident. Similar damage is well known following shock with low blood pressure, and is described under a variety of terms, such as haemoglobinuric nephrosis. This renal complication, albeit rare, underlines the important role of circulatory failure in determining the outcome.

Type 3. In the group of 7 with staphylococcal pneumonia the findings do not merit detailed description: multiple lung abscesses and bronchopleural fistulae were present in all.

\section{Treatment}

Pneumonia with early circulatory failure. When circulatory failure was severe at the time of admission, an oral endotracheal tube was passed, manual ventilation with oxygen initiated, and the airway sucked out. IPPV was begun immediately, accompanied by external cardiac massage if the peripheral pulses were not palpable. These manœuvres were synchronized so that cardiac compression coincided with the expiratory phase. The rate of ventilation was approximately 60 a minute. The airway pressure was atmospheric between inflations.

Sodium bicarbonate $8 \%$ was given intravenously $(5 \mathrm{ml} . / \mathrm{kg}$.), along with low molecular weight dextran (10 ml./kg.), and hydrocortisone $100 \mathrm{mg}$. In addition, $10 \%$ calcium chloride $1-2 \mathrm{ml}$. was usually given slowly intravenously.

If circulatory failure persisted, the following measures were taken.

(1) The oral tube was changed for a nasal endotracheal tube ${ }^{\star}$, and the patient was set up on a ventilator, since prolonged ventilation was anticipated (Rees et al., 1966).

(2) The acid-base state was measured, using the Astrup technique and capillary samples of blood (Kamath and Jones, 1966). Further bicarbonate and adjustment of ventilation was made in the light of these results.

(3) A polythene tube, 5 or 6 French gauge, was inserted into the inferior vena cava via the saphenous vein in the groin. This facilitated measurement of central venous pressure and the withdrawal of blood specimens for analysis. The tube was connected via three-way plastic taps to a saline manometer and the bottle of intravenous fluid. If necessary, additional dextran or plasma was given in order to raise the venous pressure to $10 \mathrm{~cm}$. above the midaxillary line (Jones, 1966).

(4) The urine output was measured.

Oliguria or anuria, a rising blood urea, and the recurrence of a base deficit following its correction, were taken as the indications for peritoneal dialysis.

Pneumonia with respiratory failure. All patients were given antibiotics and were nursed in a tent or incubator into which was fed a warmed, humidified oxygen-air mixture. They were tubefed when necessary. Acid-base studies were made twice daily.

The following signs of respiratory failure were regarded as the indication for more active measures: (a) considerable respiratory effort, (b) cyanosis despite oxygen enrichment, and (c) a capillary $\mathrm{PCO}_{2}$ over $70 \mathrm{~mm}$. $\mathrm{Hg}$.

The methods used to treat respiratory failure according to its severity and persistence were as

* Jackson Rees tube made by Portland Plastics Ltd., Hythe, Kent. 
follows: (1) Oral endotracheal intubation and aspiration of the airway was carried out under general anaesthesia. Induction was performed with $100 \%$ oxygen plus halothane, and intubation with intravenous suxamethonium with atropine (Bush, 1966). (2) Naso-endotracheal intubation, when repeated bronchial suction was required (Rees and Owen-Thomas, 1966). These measures were effective early in the disease when deterioration was primarily due to accumulation of mucopus in the larger airways. (3) Ventilation. The recurrence or persistence of signs of respiratory failure necessitating ventilation usually meant bronchiolar and alveolar involvement (indicated by fine râles on auscultation, and by opacities on $x$-ray examination).

Technique of ventilation. The oxygen content of the inspired gas was not allowed to exceed $70 \%$. Aspiration of material from the airway was performed as infrequently as possible. No fluid was injected into the airway, and reliance was placed upon humidified inspired air to prevent drying of secretions.

Infants were ventilated with a constant volume machine at a rate of 30 to 40 per minute. The airway pressure was measured and, if this exceeded $30 \mathrm{~cm}$. water, obstruction to the airway was treated by aspiration via a bronchial suction catheter. If the disease progressed and the amount of airway obstruction increased, the rate of ventilation was reduced to $15-20$ per minute and larger tidal volumes were used.

Termination of ventilation. The duration of ventilation was kept as short as possible. It was possible to discontinue ventilation only when, (1) there was no cyanosis when the patient was ventilated on air, (2) the $\mathrm{PCO}_{2}$ was less than $45 \mathrm{~mm} . \mathrm{Hg}$, (3) râles over the lung fields had diminished and were localized, and (4) there was $x$-ray evidence of resolution.

It was necessary to leave the endotracheal tube in place for approximately 24 hours after discontinuing ventilation in order to ensure that the infant could control his own secretions.

Staphylococcal pneumonia. Since early diagnosis is essential, treatment was begun without waiting for proof of staphylococcal origin. An unusually dense opacity in the lung field on $x$-ray was assumed to be staphylococcal in origin, and treatment was started with two antistaphylococcal agents. Usually a bactericidal drug, such as one of the penicillins, was combined with a bacteriostatic drug, erythromycin.

The indications for ventilation were the same as in other pneumonias. Accumulation of secretion in the airway due to rupture of an abscess, or the formation of a pneumothorax, may cause respiratory failure and necessitate ventilation early in the disease. Many of our patients required intubation and ventilation for this reason as a temporary measure at the time of, or soon after, admission to the Unit. The establishment of a clear airway, relief of tension pneumothorax, and correction of acid-base abnormalities, usually resulted in sufficient recovery for the patient to ventilate himself quite soon. Ventilation was avoided whenever possible once an intercostal drain with an underwater seal had been inserted.

Pus from the drainage tube was cultured daily as a guide to antiobiotic therapy. Intrapleural antibiotic therapy was continued until the pus became sterile on culture.

The underwater seal was arranged with a slight positive pressure by placing the end $2-3 \mathrm{~cm}$. underwater. If this failed to seal the fistula, a high pressure (tube $5-10 \mathrm{~cm}$. underwater), or a negative pressure $(5 \mathrm{~cm}$. or more of suction applied) was used. The aim was to close the fistula by deflating the lung or inflating it in order to bring the pleural surfaces together.

It is, therefore, essential to have a high flow and low pressure suction when applying suction to the pleural drain. Low flow and high pressure suction is required to remove pus from the airway. The suction line should, therefore, have independent flow and pressure controls.

Patency of the intercostal drainage tube must be ensured by observing a free rise and fall of fluid in the tube, though the tube may be patent when this sign is absent. The injection of air into the tube with the distal side clamped will check patency.

The blood gases should be measured frequently. Hypoxia, an increasing base deficit, and a $\mathrm{PCO}_{2}$ approaching $70 \mathrm{~mm} . \mathrm{Hg}$ are signs suggesting that ventilation may be required.

\section{Discussion}

Successful treatment of the severe pneumonias of infancy demands the institution of measures to deal with respiratory, cardiac, and renal failure before these have become serious. Intensive care in this prophylactic role is much more successful than when the same measures are used to treat an infant who has already collapsed. Early admission to a unit designed and staffed for this purpose allows close observation of the patient and ensures that measures for dealing with airway obstruction or other causes of respiratory failure are employed at the appropriate moment. 
Once the full therapeutic regimen is established, an unexpected episode of 'collapse', which may cause a serious hypoxic injury to the brain, should seldom occur. If the disease progresses despite treatment, ultimately one is confronted with the final problem of unresolved pneumonia which is the main cause of death.

The only other important cause is failure of a low cardiac output state to respond to treatment early in the natural history of the disease. This is characteristic of the group with circulatory failure described here and elsewhere (Jones, 1966).

Airway obstruction. The accumulation of mucopurulent material in the lower airway is the main cause of deterioration in the infant during the early stage of pneumonia. If left untreated it probably accounts for about $25 \%$ of the mortality of pneumonia in infancy. The care of the lower airway forms an important part of the intensive care regimen, and has been fully discussed recently by Bush (1966). Of the 70 patients, 13 were treated with a nasal endotracheal tube for lower airway obstruction, and of these only 3 died. Since 2 of these had associated congenital abnormalities (congenital heart disease and severe retrognathia), and the survivors made a complete recovery, this appears to be a satisfactory approach. No permanent laryngeal or glottic sequelae were found in a follow-up study by Owen-Thomas (1967).

Endotracheal intubation vs. tracheostomy. This has evoked much controversy (Wright and Beem, 1965; Canby and Redd, 1965; McClelland, 1965; Rees and Owen-Thomas, 1966; McDonald and Stocks, 1965; Downes, Striker, and Stool, 1966; Lancet, 1967). An endotracheal tube, provided the diameter is chosen correctly (an easy fit allowing some escape of air during positive inflation), can safely be used for one week. This means that when the tube is being used for purposes of ventilation, the condition of the patient must be such that by the fifth day the probability of terminating ventilation and extubation can be foreseen within $\mathbf{4 8}$ hours. Prolongation of ventilation beyond one week normally requires a tracheostomy.

Unresolved pneumonia. Should the child survive the two important causes of death early in the disease-respiratory failure due to airway obstruction and circulatory failure-he faces the third hazard, unresolved pneumonia. This is virtually the only cause of death during ventilation, apart from technical accidents which should be rare. The causes of unresolved pneumonia are unknown at present but the following are possible factors.
Infection. Clinical and post-mortem observations are compatible with the view that some of these deaths were due to continued progression of a virus infection. Adenovirus or respiratory syncytial virus was isolated from 4 of the 17 who died following prolonged ventilation. Bacterial infection may also have been an important cause of progressive consolidation. Secondary infection of the airway was common, but appeared to be controlled by appropriate antibiotics. However, repeated bronchial aspiration undoubtedly tends to infect the lower airway with a variety of organisms. This may delay resolution and set up a chronic bronchitis leading to delay in extubation or decannulation of a tracheostomy.

Mechanical and chemical trauma. Bronchial suction undoubtedly causes mechanical trauma if frequently repeated. The tendency of the tube to become obstructed with viscid secretion was treated at first by the installation of saline, but later by humidification of the inspired air, as being less liable to cause secondary infection. Acetyl cysteine was tried but discontinued because it appeared to perpetuate a chemical bronchitis. Steroids did not noticeably assist resolution.

Our policy now is to avoid all forms of trauma and contamination of the lower airway as far as possible, since it is all too easy to produce an iatrogenic bronchitis or bronchopneumonia.

Technique of ventilation. Positive pressure ventilation may itself contribute to failure of resolution, but there is no evidence on this point. Hyaline membrane formation was found in some but not all of those ventilated for over a week, but it was also found after short periods of ventilation in the group with circulatory failure.

Oxygen toxicity. Mixtures containing a high oxygen percentage $(>70 \%)$ were used for severe cases early in the series, and it is conceivable that this was a factor contributing to hyaline membrane formation (Nash, Blennerhassett, and Pontoppidan, 1967).

Technique of ventilation. When ventilation/ perfusion ratios are abnormal as in bronchopneumonia (Simpson and Flenley, 1967), $\mathrm{CO}_{2}$ retention is minimized by using slow ventilatory rates (Owen-Thomas, 1966). In the neonate, optimal gas exchange demands a rapid inspiratory and a long deflationary period, i.e. a ratio of 1 to 3 or 4 (Owen-Thomas, Ulan, and Swyer, 1968).

Circulatory failure. Minor degrees of circulatory failure are probably more common than is 


\begin{tabular}{|c|}
\hline $\begin{array}{c}\text { TABLE IV } \\
\text { Main Causes of Low Output } \\
\text { Circulatory Failure }\end{array}$ \\
\hline $\begin{array}{l}\text { Tissue hypoxia } \\
\text { Reduction of intravascular volume } \\
\text { Low } p H \text { due to }\left\{\begin{array}{l}\text { respiratory acidosis } \\
\text { base deficit }\end{array}\right.\end{array}$ \\
\hline
\end{tabular}

generally appreciated. The factors contributing to it are shown in Table IV. Digitalis is only indicated if the response to correction of these three factors has failed to restore a normal circulation.

The restoration of a normal arterial $\mathrm{Po}_{2}$ with assisted ventilation is not evidence that the tissues are receiving enough oxygen, for tissue perfusion may be grossly impaired by a low cardiac output. The recurrence of a base deficit which has been corrected is usually an indication that output is inadequate. Variations in output may well be the reason why Simpson and Flenley (1967) failed to find a correlation between arterial $\mathrm{Po}_{2}$ and base deficit, leading them to conclude that hypoxia may not be a potent cause of metabolic acidosis in these children.

Congestive cardiac failure was not seen unless there was associated congenital heart disease. Downward displacement of the liver and some oedema of the face is seen at times, and is due to overdistension of the lung by IPPV in subjects with less severe degrees of obstructive airway disease. It is avoided by using a minimum dead space and reducing the tidal volume so that the arterial $\mathrm{PCO}_{2}$ is not subnormal.

Renal failure. Renal failure, like circulatory failure with which it is closely interrelated, may easily be missed. It probably results from reduction of renal blood flow, and in some instances hypoxic injury to the kidney was suggested by the renal histology. The persistence or recurrence of base deficit in the absence of hypoxia should suggest renal failure. Peritoneal dialysis appears to be an effective method of treatment. The role of mannitol has not yet been sufficiently assessed.

\section{Summary}

The clinical features, management, and postmortem findings are described in 70 infants with severe bronchopneumonia, divided into 3 groups: (a) 12 presenting with severe and early circulatory failure so that the respiratory disease tended to be overlooked, (b) 45 with frank bronchopneumonia, and (c) 13 with staphylococcal pneumonia.

The role of naso-endotracheal intubation, tracheostomy, and assisted ventilation in management is evaluated.

REFERENCES

Bernstein, J., and Wang, J. (1961). The pathology of neonatal pneumonia. Amer. F. Dis. Child., 101, 350.

Bush, G. H. (1966). Aspects of pulmonary ventilation in the seriously ill child. Proc. roy. Soc. Med., 59, 1307.

Canby, J. P., and Redd, H. J., Jr. (1965). Tracheotomy in the management of severe bronchiolitis. Pediatrics, 36, 406.

Disney, M. E., Sandiford, B. R., Cragg, J., and Wolff, J. (1960). Epidemic bronchiolitis in infants. Brit. med. F., 1, 1407.

Downes, J. J., Striker, T. W., and Stool, S. (1966). Complications of nasotracheal intubation in children with croup. New Engl. f. Med., 274, 226.

Fisk, G. C. (1966). Endobronchial anaesthesia in young children. Brit. F. Anaesth., 38, 157.

Groff, D. B., Randolph, J. G., and Blades, B. (1966). Empyema in childhood. F. Amer. med. Ass., 195, 572.

Hendren, W. H., III, and Haggerty, R. J. (1958). Staphylococcic pneumonia in infancy and childhood. Analysis of 75 cases. ibid., 168, 6.

Heycock, J. B., and Noble, T. C. (1962). 1,230 cases of acute bronchiolitis in infancy. Brit. F. med., 2, 879.

High, R. H. (1957). Bronchiolitis (acute asthmatic bronchitis, acute capillary bronchitis). Pediat. Clin. N. Amer., 4, 183.

Jones, R. S. (1966). Resuscitation of the seriously ill child. Proc. roy. Soc. Med., 59, 1303.

Kamath, V. R., and Jones, R. S. (1966). Acid-base abnormalities in infants with congenital heart disease. Brit. med. F., 2, 434.

Koch, R., Carson, M. J., and Donnell, G. (1959). Staphylococcal pneumonia in children. A review of 83 cases. $\mathcal{F}$. Pediat., 55, 473.

Lancet (1967). Editorial. Endotracheal intubation or tracheostomy ? $1,258$.

McClelland, R. M. A. (196̄)). Complications of tracheostomy. Brit. med. F., 2, 567.

McDonald, I. H., and Stocks, J. G. (1965). Prolonged nasotracheal intubation. A review of its development in a paediatric hospital. Brit. F. Anaesth., 37, 161.

Morrison, B. (1955). Anoxia in the acute respiratory infections of childhood. Its recognition and treatment. Lancet, 2, 737.

Nash, G., Blennerhassett, J. B., and Pontoppidan, H. (1967). Pulmonary lesions associated with $\mathrm{O}_{2}$ therapy and artificial ventilation. New Engl. F. Med., 276, 368.

Owen-Thomas, J. B. (1966). The management of respiratory failure in childhood. M.D. Thesis, University of Liverpool.

- (1967). A follow up of children treated by prolonged nasal intubation. Canad. Anaesth. Soc. F., 14, 543.

_ Ulan, O. A., and Swyer, P. R. (1968). The effect of varying inspiratory gas flow rate on arterial oxygenation during I.P.P.V. in the respiratory distress syndrome. Brit. F. Anaesth. In the press.

Parish, W. E., Barrett, A. M., and Coombs, R. R. A. (1960a). Inhalation of cows' milk by sensitized guinea pigs in the conscious and anaesthetized state. Immunology, 3, 307.

,,--- , Gunther, M., and Camps, F. E. (1960b). Hypersensitivity to milk and sudden death in infancy. Lancet, $2,1106$.

Pryles, C. V. (1958). Staphylococcal pneumonia in infancy and childhood. An analysis of 24 cases. Pediatrics, 21, 609.

Rees, G. J., and Owen-Thomas, J. B. (1966). A technique of pulmonary ventilation with a nasotracheal tube. Brit. $\mathcal{f}$. Anaesth., 38, 901.

-, Stead, A. L., Bush, G. H., and Jones, R. S. (1966). Intensive therapy in paediatrics. Brit. med. F., 2, 1611.

Simpson, H., and Flenley, D. C. (1967). Arterial blood-gas tensions and $\mathrm{pH}$ in acute lower-respiratory-tract infections in infancy and childhood. Lancet, $1,7$.

Wright, F. H., and Beem, M. O. (1965). Diagnosis and treatment: management of acute viral bronchiolitis in infancy. Pediatrics, 35, 334. 